\title{
Outcome of Minimally Invasive Plate Osteosynthesis Technique for Humerus Diaphyseal Fractures with an Anterior Approach
}

\author{
Dr. Mahammadarif Khatri ${ }^{1}$, Dr. Sarabjeet Kohli ${ }^{2}$
}

\begin{abstract}
Background: Minimally invasive plate osteosynthesis (MIPO) technique is one of the many options for the fixation of diaphyseal fractures of the shaft of humerus using the anterior approach. We evaluated the clinical, radiographic, and functional outcome using the MIPO technique to fracture shaft of humerus. Materials and Methods: 64 adult patients with diaphyseal fractures of the humerus treated with MIPO between 2014 February and October 2016 were included in the study. Patients with metabolic bone disease, polytrauma, and Gustilo and Anderson type 3 open fractures with injury severity score >16 were excluded from the study. All cases were treated with closed indirect reduction and locking plate fixation using the MIPO technique. The surgery time, radiation exposure, and time for union was noted. The shoulder and elbow function was assessed using the UCLA shoulder and Mayo elbow performance scores, respectively. Results: Of the 64 patients in the study, 38 were males and 26 were females. The mean age was 39 years (range: 22-70 years). 40 of the 64 (84.3\%) had the dominant side fractured. We had 16 cases of C2 type; 10 cases of C1 and 10 cases of A2 type; 8 cases of B2 type; 6 cases each of B3, B1, and A1 type; and 2 cases of A3 type of fracture. The mean surgical time was 94.5 minutes (range: 70-120 minutes) and mean radiation exposure was 160.3 seconds (range: 100-220 seconds). The mean radiological fracture union time was 12.9 weeks (range: 10-20 weeks). Shoulder function was excellent in 54 cases (84.3\%) and good in remaining 10 cases $(15.6 \%)$ on the UCLA score. Elbow function was excellent in 52 cases $(81.2 \%)$, good in 10 cases (15.6\%), and fair in 2 case (3.1\%) who had an associated olecranon fracture that was fixed by hook plate in the next sitting.
\end{abstract}

Keywords: Minimally Invasive Plate Osteosynthesis in diaphyseal fractures in humerus

\section{Introduction}

Humeral shaft fractures constitute around $3-5 \%$ of all fractures[19]. Open reduction and internal fixation (ORIF) is the gold standard for surgical treatment. The advantages include anatomical reduction of fractures and less interference to elbow and shoulder function [1, 2]. Disadvantages of this technique are extensive soft tissue stripping and disruption of periosteal blood supply, and hence the risk of non-union. Iatrogenic radial nerve palsy is another major disadvantage $[3,4] \mathrm{We}$ aimed at adequate healing and early functional rehabilitation of the limb though compromising precise reduction and absolute stable fixation. Stable mechanical fixation requires precise reduction and opening of the fracture site. It heals by primary intention which is biologically inferior to healing by a secondary intention with the preservation of the fracture haematoma causing minimal soft tissue injury $[5,6]$. With progressive improvements over the years in the surgical techniques, the conservative methods of reduction and stabilisation have given way to internal fixation with the plate and screws despite their drawbacks [7, 8] There has been evidence to show the superiority of biological fixation over a stable mechanical fixation.[9] This lead to the development and improvement in the techniques of biological fixation for fractures and also the development of stabilization systems that help in achieving a biological fixation, [10,11] The minimally invasive plate osteosyntesis (MIPO) of humerus shaft fracture has shown promising results recently.[12-15]

\section{Materials and Methods}

64 diaphyseal fractures of humerus were treated with MIPO technique, in a prospective study between February 2014 and October 2016 at our centre. The cases were followed up for a minimum period of 2 years at department of orthopaedics, mgm medical college and hospitals , navi Mumbai .

The inclusion criterion was displaced diaphyseal fracture of humerus between 21 and 75 years and who consented to participate in the study. The operative procedure was performed within 5 days of the injury. Patients with metabolic bone disease, polytrauma, and Gustilo and Anderson type 3 open fractures with injury severity score $>16$ were excluded from the study. All cases were treated with closed indirect reduction and locking plate fixation using the MIPO technique. The surgery time, radiation exposure, and time for union was noted. The shoulder and elbow function was assessed using the UCLA shoulder and Mayo elbow performance scores, respectively

\section{UCLA Score for Shoulder}

\begin{tabular}{|c|c|c|}
\hline \multirow{6}{*}{ Pain } & $\begin{array}{l}\text { Present all of the time and unbearable, } \\
\text { strong medication frequently }\end{array}$ & 1 \\
\hline & $\begin{array}{l}\text { Present all the time but bearable, strong } \\
\text { medication occasionally }\end{array}$ & 2 \\
\hline & $\begin{array}{c}\text { None or little at rest, present during light } \\
\text { activities; salicylates frequently }\end{array}$ & 4 \\
\hline & $\begin{array}{l}\text { Present during heavy or particular } \\
\text { activities only; salicylates occasionally }\end{array}$ & 6 \\
\hline & Occasional and slight & 8 \\
\hline & None & 10 \\
\hline \multirow{6}{*}{ Function } & Unable to use limb & 1 \\
\hline & Only light activities possible & 2 \\
\hline & $\begin{array}{l}\text { Able to do light housework or most } \\
\text { activities of daily living }\end{array}$ & 4 \\
\hline & $\begin{array}{l}\text { Most housework, shopping, and driving } \\
\text { possible; able to do hair and dress and } \\
\text { undress, including fastening brassiere }\end{array}$ & 6 \\
\hline & $\begin{array}{c}\text { Slight restriction only; able to work } \\
\text { above shoulder level }\end{array}$ & 8 \\
\hline & Normal activities & 10 \\
\hline Active forward & $150^{\circ}$ or more & 5 \\
\hline
\end{tabular}

\section{Volume 6 Issue 12, December 2017}




\section{International Journal of Science and Research (IJSR) \\ ISSN (Online): 2319-7064}

Index Copernicus Value (2016): 79.57 | Impact Factor (2015): 6.391

\begin{tabular}{|c|c|c|}
\hline \multirow[t]{5}{*}{ flexion } & $120-150^{\circ}$ & 4 \\
\hline & $90-120^{\circ}$ & 3 \\
\hline & $45-90^{\circ}$ & 2 \\
\hline & $30-45^{\circ}$ & 1 \\
\hline & $<30^{\circ}$ & 0 \\
\hline \multirow{6}{*}{$\begin{array}{c}\text { Strength of } \\
\text { forward flexion } \\
\text { (manual } \\
\text { muscle-testing) }\end{array}$} & Grade 5 (normal) & 5 \\
\hline & Grade 4 (good) & 4 \\
\hline & Grade 3 (fair) & 3 \\
\hline & Grade 2 (poor) & 2 \\
\hline & Grade 1 (muscle contr.) & 1 \\
\hline & Grade 0 (nothing) & 0 \\
\hline \multirow{2}{*}{$\begin{array}{c}\text { Satisfaction of } \\
\text { the patient }\end{array}$} & Satisfied and better & 5 \\
\hline & Not satisfied and worse & 0 \\
\hline \multirow{3}{*}{ Result } & 34-35 points & $\begin{array}{c}\text { excell } \\
\text { ent }\end{array}$ \\
\hline & $29-33$ points & good \\
\hline & $<29$ points & poor \\
\hline
\end{tabular}

\section{Operative procedure}

The supine position was given under general anesthesia, with the arm abducted to $90^{\circ}$ and the forearm in full supination. The image intensifier was positioned on the same side of the operating table as the arm to be operated. Then 3-cm incision between the proximal biceps and medial border of the deltoid, $6 \mathrm{~cm}$ distal to the anterior part of the acromion process was made. Dissection was carried to the humerus. Distally, a $3-\mathrm{cm}$ incision was made along the lateral border of the biceps, approximately $5 \mathrm{~cm}$ proximal to the flexion crease. The site of incision was confirmed under the image intensifier and altered, if necessary, to be as far as away as possible from the fracture site. The biceps was retracted medially to expose the musculocutaneous nerve, and which overlies the brachialis muscle. The brachialis muscle was split and the musculocutaneous nerve retracted medially, and the radial nerve was protected by the lateral half of the brachialis muscle. A sub-brachialis, extra-periosteal tunnel was created by passing an artery forceps, used as the tunneling instrument, deep to the brachialis muscle from the distal to the proximal incision. And care was taken to pass the tunneling instruments anteriorly or anteromedially to avoid chances of injury to the radial nerve. After creating the tunnel, the LCP of the template length was passed through the tunnel. The plate position and reduction was visualized on the image intensifier. Manual traction was applied to restore the length and correct varus/valgus angulation and rotation. The plate was temporally fixed to the bone with $2.0-\mathrm{mm} \mathrm{K}$-wires. Ensuring that the position of the plate on the distal fragment was the central, it was fixed with a locking screw and, similarly, the proximal fragment was also fixed. After confirmation of the reduction alignment, the fixation was completed with a minimum of two screws in both fragments. Deciding the appropriate amount of force to be used for manual traction to achieve adaptation of the fragments was not easy at first; this was something we had to slowly master as the study progressed. The rotational deformity was minimized using the 'cortical step sign' and the 'diameter difference sign' described by Krettek.[18] None of the patients required bone grafting or bone substitute at primary surgery. The operative time (defined as the time, from the skin incision to wound closure) and duration of radiation exposure (in seconds) was recorded though the doses were not calculated.

\section{Post Operative care}

Immobilisation was done with the arm-pouch. Mobilisation is started as soon as the pain permitted the patient to do so. Simple pendulum exercises were adviced after post operative day 3. The patients were followed up as per protocol. The union time based on callus formation at the fracture site as per radiological follow-up with anteroposterior and lateral views were noted. Union was considered achieved with the presence of bridging callus in three of the four cortices seen on the anteroposterior and lateral radiographs and clinically, by abscence of pain at the fracture site. Functional assessment of shoulder and elbow were done using the UCLA Score and MEPI Score, respectively $[19,20]$ with due care to note any of the possible post-operative complications. The patients were followed up and reviewed at monthly intervals for the initial few months till the callus formation and fracture union, then once every 3 months till 18 months. The grading of UCLA shoulder score was followed as per the standards as excellent (34-35 points), good (29-33 points), fair (21-28 points), and poor (0-20 points). Function of elbow was graded on the basis of MEPI Score into excellent ( $\geq 90$ points), good (75-89 points), fair (60-74 points), or poor ( $<60$ points).

Radiographic measurements were performed on standard anteroposterior and lateral radiographs to assess fracture union or for any potential loss of fracture reduction. Union was defined as the absence of pain and the presence of bridging callus in three of the four cortices seen on the anteroposterior and lateral radiographs

\section{Results}

The mean age was 39 years (range 22-70 years). 38 $(59.3 \%)$ were males and $26(40.6 \%)$ females. 54 cases $(84.3 \%)$ had injury in their dominant arm. We had 16 cases of $\mathrm{C} 2$ type; 10 cases of $\mathrm{C} 1$ and $\mathrm{A} 2$ type; 8 cases of $\mathrm{B} 2$ type; 6 cases of B3, B1, and A1 type; and 2 case of A3 type of fractures. Road traffic accident was the most common mode of injury, being reported by $52(81.2 \%)$ cases; the rest sustained injury following fall on an outstretched hand ( 8 cases) and direct trauma (4 cases). The mean surgical time was 91.5 minutes (range: $70-120$ minutes) and the mean radiation exposure was for 160.3 seconds (range: 100-220 seconds). We accepted up to $5^{\circ}$ of varus/valgus angulation intraoperatively and on following these patients up, in 50 $(78.1 \%)$ of the cases the angulation had remodeled to correct alignment. In the remaining 14 cases, 4 had $3^{\circ}$ of varus, 6 had $3^{\circ}$ valgus, and 4 case had $5^{\circ}$ varus angulation at the end of 2 years; however, this did not affect their functional outcome. 
International Journal of Science and Research (IJSR)

ISSN (Online): 2319-7064

Index Copernicus Value (2016): 79.57 | Impact Factor (2015): 6.391

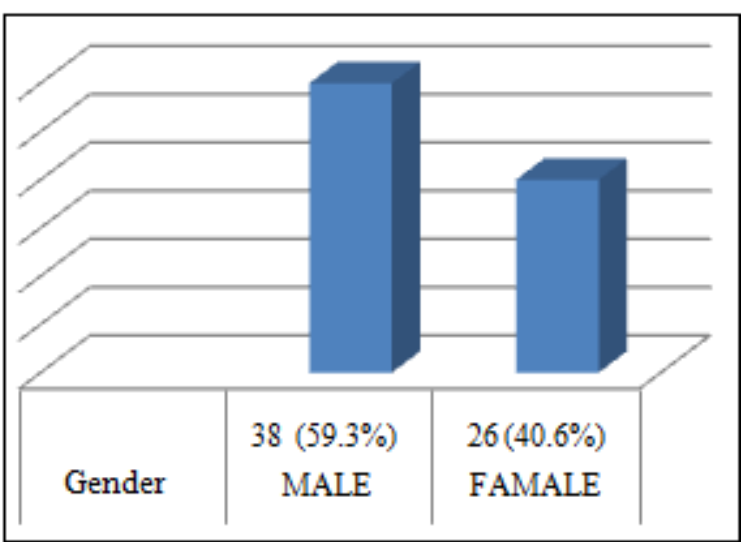

Gender Ratio

\begin{tabular}{|c|c|c|}
\hline & No. of Cases & Outcome \\
\hline Excellent & 54 & $84.3 \%$ \\
\hline Good & 10 & $15.6 \%$ \\
\hline Fair & - & - \\
\hline
\end{tabular}

UCLA SCORE

\begin{tabular}{|c|c|c|}
\hline & No. of Cases & Outcome \\
\hline Excellent & 52 & $81.2 \%$ \\
\hline Good & 10 & $15.6 \%$ \\
\hline Fair & 2 & $3.1 \%$ \\
\hline
\end{tabular}

\section{Elbow Function Score}

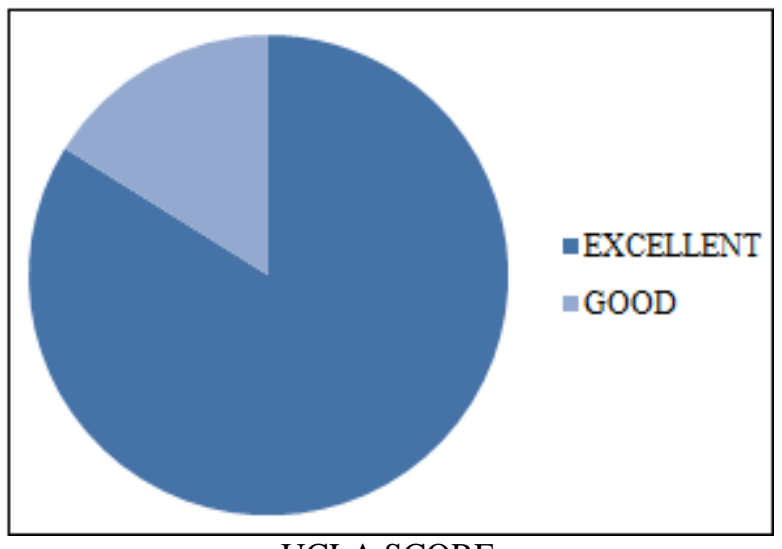

UCLA SCORE

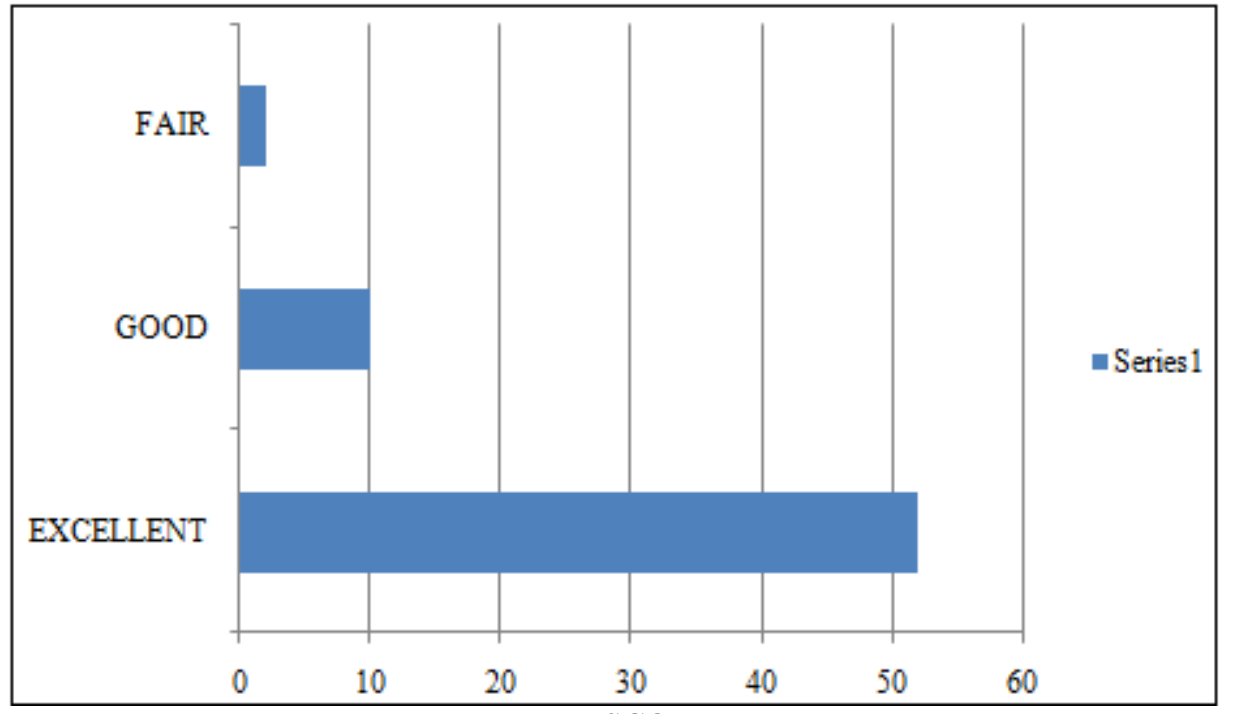

MEPI SCORE

\section{Discussion}

Minimally invasive technique for fracture treatment has evolved based on the idea that with the preservation of fracture haematoma and the vascularity around the fracture site, new bone is layed down in the form of callus, a fact which was recognised by Albrecht Haller's (1708-1777) [13] led to the success of the MIPPO technique for fracture fixation at other sites and lies in the fact that using long plates across zones of extensive fracture fragmentation with only few screws on either side of the fracture which withstands considerable deforming forces, though the tension side for shaft of humerus and the expected placement of the plate lies posteriorly where the plate should be placed, according to principles. The idea has evolved from the knowledge of the fact that with minimal stress per unit area, the bending stllowing successful fixation as the construct becomes elastic [20,21]. MIPPO is technically demanding and needs intraoperative imaging in order to obtain adequate fracture alignment. Scarring of brachialis muscle and inadequate postoperative rehabilitation, contribute to limited elbow range of motion. Long plates used to bridge an extensive zone of fragmentation with only short fixation on either end of the bone can achieve union at the fracture site by callus formation provided the fracture haematoma is undisturbed. This process is augmented by micromotion at the fracture site.

The advantage of MIPPO over open reduction and plate fixation of fractures of shaft of humerus is less surgical trauma to the soft tissue and maintaining the periosteal circulation contrary to the method of application of the plate on the bone by an open technique which interferes with the local vascularization, leading to the possible osteonecrosis beneath the implant, ending up in delayed healing or non-

\title{
Volume 6 Issue 12, December 2017
}

\author{
www.ijsr.net
}

Licensed Under Creative Commons Attribution CC BY 


\section{International Journal of Science and Research (IJSR) \\ ISSN (Online): 2319-7064}

Index Copernicus Value (2016): 79.57 | Impact Factor (2015): 6.391

union. The potential to remodel is much higher after secondary bone healing following MIPPO fixation and fracture unionThe brachialis muscle covers the humerus anteriorly and protects the radial nerve from injury when a plate is inserted submuscularly. The radial nerve follows a fixed course, anatomically [5]

According to Apivatthakakul et al. [12] "when a plate is placed on the anterior side of the humeral shaft, the mean distance from the closest part of the plate to the radial nerve is $3.2 \mathrm{~mm}$. and on pronation of the forearm, the radial nerve was noted to move medially closer to the distal end of the plate and was at risk of iatrogenic injury". For this reason, the supination position of the forearm should be maintained during the entire procedure. The study of postoperative ultrasonographic measurement of the distance between the radial nerve and the implant used in the MIPPO technique by Livani et al. substantiates this fact[22]. There was no case of superficial or deep infection in our study. Concha et al. [23] studied a series of 35 patients who underwent MIPO for humerus shaft fractures and reported the occurrence of only one deep and one superficial infection, which represents a 6\% infection rate. According to Hadhoud MM. Et al. [24] there was no infection in the MIPO group.

\section{Conclusion}

MIPO is a complex technique, requiring arelatively long learning curve. However, the results are good and reproducible and there are few risks. The plate placement and indirect reduction requires experience though MIPPO after anterior approach is the safe and reproducible option and also respects the principles of biological fixation with minimal soft tissue dissection, preserves fracture haematoma and periosteal blood supply, and is more forgiving in comminuted fractures of the diaphysis. Fracture union in complex fractures is achieved easily and in shorter operative time with less risk of infection.

\section{References}

[1] Niall DM, O'Mahony J, McElwain JP. Plating of humeral shaft fractures - has the pendulum swung back? Injury. 2004; 35:580-586.

[2] Bhandari M, Devereaux PJ, McKee MD, Schemitsch EH. Compression plating versus intramedullary nailing of humeral shaft fractures a meta-analysis Acta Orthop. 2006; 77:279-284

[3] Lim KE, Yap CK, Ong SC, Aminuddin M. Plate osteosynthesis of the humerus shaft fracture and its association with radial nerve injury a retrospective study in Melaka General Hospital. Med J Malaysia. 2001; 56:8-12.

[4] Paris H, Tropiano P, Clouet D'orval B, Chaudet H, Poitout DG. Fractures of the shaft of the humerus: systematic plate fixation. Anatomic and functional results in 156 cases and a review of the literature Rev Chir Orthop Reparatrice Appar Mot. 2000; 86:346-359.

[5] Apivatthakakul T, Arpornchayanon O, Bavornratanavech S. Minimally invasive plate osteosynthesis (MIPO) of the humeral shaft fracture: Is it possible? A cadaveric stud and preliminary report Injury. 2005; 36:530-8.

[6] Zhiquan A, Bingfang Z, Yeming W, Chi Z, Peiyan H. Minimally invasive plating osteosynthesis (MIPO) of middle and distal third humeral shaft fractures, J Orthop Trauma. 2007; 21:628-33.

[7] Ziran BH, Belangero W, Livani B, Pesantez R. Percutaneous plating of the humerus with locked plating: Technique and case report. J Trauma Inj Infect Crit Care. 2007; 63:205-10.

[8] Livani B, Belangero W, Andrade K, Zuiani G, Pratali R. Is MIPO in humeral shaft fractures really safe? Postoperative ultrasonographic evaluation Int Orthop. 2009; 33:1719-23.

[9] Baumgaertel F, Buhl M, Rahn BA. Fracture healing in biological plate osteosynthesis. Injury 1998;29 (Suppl 3): $\mathrm{C} 3-6$.

[10]Dickson KF, Munz JW. Locked plating: Biomechanics and biology. Tech Orthop 2007;22:4.

[11] Wagner M, Frenk A, Frigg R. Locked plating: Biomechanics and biology and locked plating: Clinical indications. Tech Orthop 2007;22:4.

[12] Apivatthakakul T, Arpornchayanon O, Bavornratanavech S. Minimally invasive plate osteosynthesis (MIPO) of the humeral shaft fracture: Is it possible? A cadaveric study and preliminary report. Injury 2005;36:530-8.

[13]Zhiquan A, Bingfang Z, Yeming W, Chi Z, Peiyan H. Minimally invasive plating osteosynthesis (MIPO) of middle and distal third humeral shaft fractures. J Orthop Trauma 2007;21:628-33.

[14]Ziran BH, Belangero W, Livani B, Pesantez R. Percutaneous plating of the humerus with locked plating: Technique and case report. J Trauma Inj Infect Crit Care 2007;63:205-10.

[15] Livani B, Belangero W, Andrade K, Zuiani G, Pratali R. Is MIPO in humeral shaft fractures really safe? Postoperative ultrasonographic evaluation. Int Orthop 2009;33:1719-23.

[16] Baker SP, O’Neill B, Haddon W Jr, Long WB. The injury severity score: A method for describing patients with multiple injuries and evaluating emergency care. J Trauma 1974;14:187-96.

[17] Muller ME, Nazarian S, Koch P, Schatzker J. The comprehensive classification of fractures of the long bones New York: Springer, 1990.

[18] Krettek C, Miclau T, Grün O, Schandelmaier P, Tscherne H. Intraoperative control of axes, rotation and length in femoral and tibial fractures-Technical note. Injury. 1998;29(Suppl 3): C29-39.

[19] Wagner M, Frenk A, Frigg R. Locked plating: Biomechanics and biology and locked plating: Clinicalindications Tech Orthop. 2007; 22:4.

[20] Baumgaertel F, Buhl M, Rahn BA. Fracture healing inbiological plate osteosynthesis Injury. 1998; 29(3):C3-6.

[21]Dickson KF, Munz JW. Locked plating: Biomechanics and biology Tech Orthop. 2007; 22:4

[22] Livani B, Belangero W, Andrade K, Zuiani G, Pratali R. Is MIPO in humeral shaft fractures really safe? Postoperative ultrasonographic evaluation Int Orthop. 2009; 33:1719-23. 


\section{International Journal of Science and Research (IJSR) \\ ISSN (Online): 2319-7064}

Index Copernicus Value (2016): 79.57 | Impact Factor (2015): 6.391

[23] Concha JM, Sandoval A, Streubel PN. Minimally invasive plate osteosynthesis for humeral shaft fractures: are results reproducible? Int Orthop. 2010; 34:1297-1305.

[24] Hadhoud MM, Darwish AE, Mesriga MM. Minimally invasive plate osteosynthesis versus open reduction and plate fixation of humeral shaft fractures. Menoufia Med J. [serial online] 2015; 28:154-61.

Volume 6 Issue 12, December 2017

www.ijsr.net

Licensed Under Creative Commons Attribution CC BY 